\title{
O PROCESSO SAÚDE-DOENÇA E O CUIDADO DOMICILIÁRIO AO PORTADOR DE DOENÇA DE ALZHEIMER
}

THE HEALTH-DISEASE PROCESS AND THE HOME CARE OF ALZHEIMER'S DISEASE BEARER

\author{
EL PROCESO SALUD-ENFERMEDAD Y EL CUIDADO DOMICILIAR \\ PARA LA PERSONA AFECTADA POR LA ENFERMEDAD DE ALZHEIMER
}

Aline Miranda da Fonseca* Enedina Soares**

\footnotetext{
* Enfermeira, Mestranda em Enfermagem do Programa de Pós-Graduação em Enfermagem, Universidade Federal do Estado do Rio de Janeiro/UNIRIO.
}

** Enfermeira. Livre Docente e Prof. permanente do Programa de Pós-Graduação em Enfermagem, UNIRIO.

RESUMO. Este estudo propõe uma abordagem sobre o processo saúde - doença dando enfoque ao processo degenerativo / demencial da doença de Alzheimer, ressaltando a condição de dependência advinda desta doença. Destaca o papel da família no cuidado domiciliário, como também a necessidade de o enfermeiro incluir a família no planejamento das ações de cuidado prestado no ambiente domiciliar.

PALAVRAS-CHAVE: processo saúde-doença; assistência domiciliar; enfermeiro; doença de alzheimer.

ABSTRACT. This study proposes an analysis about the health-disease process focused on the degenerative / demencial process of the Alzheimer's disease, emphasizing the dependence condition which results of the disease. It stands out the family role at the home care, as also the nurse's need of including family in the care planning actions at home environment.

KEYWORDS: health-disease process; home nursing; alzheimer's disease.

RESUMEN. Este estudio propone un abordaje sobre el proceso salud-enfermedad, con énfasis en el proceso degenerativo / demencial de la enfermedad de Alzheimer, acentuando la condición de dependencia resultante de la enfermedad. Destaca la función de la familia en el cuidado domiciliar, como también la necesidad del enfermero incluir la familia en el planeamiento de las acciones de cuidado realizadas en el ambiente domiciliar.

PALABRAS-CLAVE: proceso salud-enfermedad; atención domiciliaría de salud; enfermero; enfermedad de alzheimer.

Recebido em: 09/02/2006

Aceito em: 11/04/2006
Aline Miranda da Fonseca

Travessa Eng. ${ }^{\circ}$ Guilherme Greenhalg, 21/502 - Icaraí/Niterói E-mail: alinemf10@hotmail.com

Tel: (21) 92750881 


\section{INTRODUÇÃO}

Enquanto profissionais de saúde - enfermeiras deparamo-nos diariamente com experiências humanas e individuais sobre vida e morte, saúde e doença, aspectos intrínsecos dos seres humanos no decorrerl acontecer da vida.

Dessa forma, a doença e a morte estão presentes na existência humana. Essas condições revelam a fragilidade do indivíduo e são geradores de dor e sofrimento. Os acontecimentos com o corpo repercutem na existência do ser no mundo, porque o corpo constitui sua presença no mundo perante o outro, significa o ser encarnado convivendo com o outro ${ }^{1}$. Já o entendimento de saúde é um movimento de autotranscendência da pessoa em direção a uma expressão de vida que suporta a simples homeostase dos subsistemas do organismo humano ${ }^{2}$.

Entretanto, para compreendermos os aspectos multidimensionais que permeiam o processo saúde-doença, devemos considerar que:

As ações e reações dos seres humanos estão estreitamente relacionadas à elaborações que fazem de suas experiências de vida e dos significados que atribuem a elas, no fluxo da rede de contínuas interações sociais estabelecidas cotidianamente, evidenciando o homem como ator social a ser assim considerado em todas as abordagens dos processos que o envolvem ${ }^{3: 92}$.

Percebe-se então que a concepção de saúde e doença é assumida para cada ser humano, diferentemente, já que cada um possui história de vida peculiar e o que é considerado normal para um indivíduo pode não ser para o outro. Essa idéia pode ser complementada ao destacar que os indivíduos criam sentidos para os fatos de suas vidas; entre eles a doença, a saúde, a vida, a morte ${ }^{2}$.

Dentro desse contexto, a família possui maneiras próprias de desenvolver o cuidado, pois possui saberes individuais sobre saúde, doença, enfermidade. Esses saberes possuem valores e crenças próprias de cada indivíduo ou grupo familiar.
A vida é biológica, social e culturalmente construída; portanto pode-se dizer que os estágios da vida apresentam diferentes significados e duração ${ }^{4}$.

Buscamos, pois, como objetivo deste estudo, abordar o cuidado domiciliário ao idoso portador de doença de Alzheimer, incluindo a família no planejamento das ações desse cuidado.

\section{PROCESSO DEMENCIAL E CUIDADO}

A demência é atualmente reconhecida como síndrome caracterizada por deteriorização intelectual que ocorre em adultos e é tão severa que interfere com o desenvolvimento social da pessoa ${ }^{5}$.

A doença de Alzheimer ou demência senil do tipo Alzheimer pode ser entendida como uma doença neurológica progressiva e irreversível, com início insidioso, caracterizada por perdas gradativas da função cognitiva e distúrbios do comportamento e do afeto ${ }^{6}$. Esta demência interfere na atividade da vida diária e social do idoso enfermo, conferindo-Ihe dependência e conseqüentemente necessidade de cuidados/ações direcionadas.

Então, o cuidador torna-se o indivíduo mais importante desse processo, sendo responsável por todos os cuidados que envolvem o idoso. O indivíduo que assume o papel de cuidar possui uma concepção de saúde e doença que está diretamente associada à maneira como ele, no decorrer de sua história de vida, foi apropriando-se da natureza para transformála, buscando atender às suas necessidades.

A concepção de saúde e doença dá suporte aos projetos de intervenção sobre a realidade; isto é, a prática cotidiana de assistência junto aos indivíduos e aos grupos sociais é orientada pela visão que se tem de saúde, doença, vida, trabalho, entre outros ?

É vista, então, a necessidade do enfermeiro conhecer e compreender a realidade da vida diária do cuidador do idoso com doença de Alzheimer, resgatando valores de vida, condições sociais e formas de enfrentamento de problemas. Dessa, forma faz sobressair que o cuidado da família implica 
interjogo de valores, crenças e experiências, porque cada família apresenta suas próprias peculiaridades e construções ${ }^{8}$.

Percebe-se, dessa forma, que a assistência à saúde de pessoas idosas com enfermidades que exigem período prolongado de tratamento e acompanhamento, especificamente a doença de Alzheimer, requer do enfermeiro conhecimento, adequação e aplicação de uma abordagem que inclua a família no planejamento das ações de cuidado.

\section{A FAMÍLIA - CERNE DO PAPEL DO CUIDAR}

Os seres humanos se organizam socialmente, formando uma rede de laços e/ou relações interpessoais, constituindo família, grupos ou comunidades. A rede social natural e básica é a família, estrutura nuclear em que todos estamos insertos, a partir do momento em que nascemos ${ }^{9}$.

O significado de família pode ser entendido como: a) pessoas aparentadas que vivem, em geral na mesma casa, particularmente o pai, a mãe e os filhos; b) grupo de indivíduos que professam o mesmo credo, têm os mesmos interesses, a mesma profissão, quando não são também do mesmo lugar de origem; c) grupo formado por indivíduos que são ou se consideram consangüíneos uns em relação aos outros, ou que descendem de um tronco ancestral comum ou que sejam ainda estranhos, admitidos por adoção ${ }^{10}$.

Concordamos quando é ressaltado que é com base nesses conceitos, que se designa, dentro da família, um membro principal, com possibilidade de atuar na modalidade do cuidador familiar ${ }^{11}$.

Observa-se, atualmente, intensa transformação na estrutura familiar, nos padrões tradicionais das funções familiares, devido a implicações sociais, econômicas e demográficas. Dentro dessa perspectiva, os cuidados oriundos de redes informais de apoio, constituídas por filhos, parentes e amigos representam a mais importante fonte de atenção ao idoso.

O vínculo do cuidador familiar com o idoso enfermo é uma tendência que a cultura familiar reforça, e até se assegura no texto constitucional em seu artigo 229: “(...) os filhos maiores têm o dever de ajudar e amparar os pais na velhice, carência ou enfermidades" ${ }^{12}$. O Estatuto do Idoso, em seu artigo $3^{\circ}$, parágrafo $\mathrm{V}$, reafirma esta questão ao abordar a "priorização do atendimento do idoso por sua própria família".

Historicamente, a sociedade responsabiliza a família pelos cuidados prestados ao idoso. As repercussões, significados e abordagens do cuidado domiciliário ao idoso para a família são inúmeros, quando a função do cuidar não é adequadamente realizada, a família sofre sanções sociais, sendo considerada negligente e/ou irresponsável ${ }^{5}$.

É importante considerarmos que, além das questões culturais arraigadas na socieadade e pela sociedade, existe também o aspecto religioso. Esse aspecto está inserto na sociedade e conseqüentemente no núcleo familiar, sustentando a idéia da responsabilidade da família sobre os idosos. Neste contexto, é importante destacar que o cuidado é uma produção artesanal, portanto, cultural.

O relacionamento entre idosos e sua família varia de cultura para cultura; porém, na maioria das sociedades, existe a valorização da interação intergeracional como uma das bases da construção da cultura ${ }^{5}$.

Ao buscarmos respaldo em literatura sobre este assunto, encontramos em Néri ${ }^{13}$, Néri e Carvalho ${ }^{14}$, que a ordem culturalmente estabelecida para desempenhar o papel de cuidar é preferencialmente da esposa; em segundo lugar na hierarquia do compromisso vêm os descendentes da segunda geração. Neste caso, o candidato mais provável é a filha mais velha. Em seguida na hierarquia vem a viúva, depois a solteira de meia idade, com ou sem filhos. Raramente o cuidador é outro parente ou uma pessoa mais jovem, e mais raramente ainda é o homem.

Dessa forma, é visto que a família é parte integrante de um ambiente sociocultural, em que significados, valores, crenças, saberes e práticas são 
organizados e concebidos e ao mesmo tempo são partilhados. Essa abordagem se sobressai, quando se ressalta que na tentativa de compreender e analisar saúde e doença, em qualquer sociedade, comportamentos individuais, interações e estrutura social precisam ser colocados em contexto cultural ${ }^{3}$.

Portanto percebemos a necessidade premente de conhecermos e aprimorarmos o cuidado direcionado à família, principalmente à família cuidadora de um doente de Alzheimer, pois ao reconhecer a família como unidade social bastante complexa; e ainda acrescentar que a diversidade dos aspectos que a envolvem nos faz reconhecer que somente conhecemos parte de sua realidade ${ }^{15}$.

\section{CONSIDERAÇÕES FINAIS}

O cuidar do idoso no ambiente domiciliar é tendência mundial. A longevidade do ser humano, em nosso país, impõe a necessidade de um novo olhar para essa população. Autores destacam o aumento do número de idosos no Brasil, atribuindo à demência um importante problema de saúde pública. Ao realizarem uma estimativa, apontaram que $85 \%$ dos idosos apresentam pelo menos uma doença crônica. Desses $85 \%$, prevê-se que pelo menos 10\% possuam no mínimo cinco afecções concomitantes ${ }^{16 ; 17 .}$

Nesse contexto, o portador de doença de Alzheimer torna-se progressivamente dependente, necessitando de cuidados contínuos. Os transtornos demenciais, especialmente a demência do tipo Alzheimer, além de provocar sérias alterações/ mudanças na vida do portador, causa grande sofrimento a sua família, fazendo com que esta se reorganize estruturalmente e internamente para prestar cuidados ao seu ente querido, que se torna progressivamente dependente.

Ao se tratar da doença enquanto processo, têm - se uma perspectiva mais compreensiva, incorporando os indivíduos e suas famílias, na medida que tomam contato, respondem e se adaptam aos sintomas e deficiências. A experiência da doença enquanto processo visa integrar corpo e mente e inseri-los num contexto sociocultural, muito além de uma entidade fisiológica ${ }^{3: 92}$.

O enfermeiro deve estar atento para o binômio idoso demenciado e sua família - no processo degenerativo do tipo Alzheimer, instrumentalizando o cuidador nas atividades e necessidades diárias do cuidado, e ainda orientando - o a adaptarse às necessidades impostas pelo cotidiano durante o processo demencial, no qual é deflagrada a dependência.

Desta forma, repensar o cuidado domiciliário do portador de Doença de Alzheimer é de fundamental importância para a enfermagem contemporânea, inserida neste novo contexto de maior envelhecimento populacional e conseqüente maior expectativa de vida.

\section{REFERÊNCIAS}

1 Vasconi R. La salud como problema existencial. In: Motta MG. Cuidado humanizado no ensino de enfermagem. Rev Bras Enferm. Brasília: Distrito Federal; 2004. Nov/dez;57(6):758-60.

2 Vicini G. Abraço afetuoso em corpo sofrido: Saúde integral para idosos. São Paulo: SENAC; 2002.

3 Gualda D, Bergamasco R. Processo saúde - doença: Evolução de um conceito. In: Gualda e Bergamasco. Enfermagem, cultura e o processo saúde - doença. São Paulo: Ícone; 2004. p. 92.

4 Bretâs ACP. Cuidadores de idosos e o Sistema Único de Saúde. Rev Bras Enferm. Brasília: Distrito Federal; 2003, Maio/jun; 56(3):298-301.

5 Caldas CP. Contribuindo para a construção da rede de cuidados: trabalhando com a família do idoso portador de síndrome demencial. Textos sobre envelhecimento. V. 4, n. 8. Rio de Janeiro; 2002. Disponível em: $<$ www.unati.uerj.br/tse/scielo>. (13 jun 2005).

6 Brunner, Suddarth. Tratado de enfermagem médico cirúrgica. 8. ed. Rio de Janeiro: Guanabara Koogan; 1998.

7 Fracolli LA, Bertolozzi MR. Abordagem do processo saúde - doença das famílias e do coletivo. Disponível em:< http://ids-saude.uol.com.br/psf/enfermagem/tema1/ texto1> (11 mai 2002).

8 Delgado J. A família vivenciando situações de saúde doença: um conhecimento em construção. In: Elsen; Marcon; Santos.O Viver em família e sua interface com a saúde e a doença. Maringá: Eduem; 2002. 
9 Campos EP. Quem cuida do cuidador: uma proposta para os profissionais de saúde. Petrópolis:Vozes; 2005.

10 Ferreira $\mathrm{ABH}$. Novo Dicionário Aurélio da Língua Portuguesa. 2. ed. Rio de Janeiro: Nova Fronteira; 1986.

11 Soares E, Fialho AVM. Refletindo sobre o cuidado domiciliar, a partir da prática. Rev Esc Enferm Anna Nery. Rio de Janeiro; 2001; 5(3): 289-94.

12 Constituição Federal (BR). 7. ed. Revisão atual. São Paulo: Revista dos Tribunais; 2003.

13 Neri AL.,organizadores. Cuidar de idosos no contexto da família: questões psicológicas e sociais. Campinas (SP): Alínea; 2002.
14 Neri AL, Carvalho VAML. O bem - estar do cuidador: aspectos psicossociais. In: Freitas EV. et al. Tratado de geriatria e gerontologia. Rio de Janeiro: Guanabara Koogan; 2002. p.778-89.

15 Althoff CR. Delineando uma abordagem teórica sobre o processo de conviver em família. In:Elsen, Marcon e Santos. O viver em família e sua interface com a saúde e a doença. Maringá: Eduem; 2002.

16 Menezes P, Garrido R. Impacto em cuidadores de idosos com demência atendidos em um serviço psicogeriátrico. Rev Saúde Pública. 2004; 36(6): 835-41.

17 Ramos LR. Epidemiologia do envelhecimento. In: Freitas $E V$. et al. Tratado de geriatria e gerontologia. Rio de Janeiro: Guanabara Koogan; 2000. p.72-8. 